\title{
Physico-Chemical Processes of Interaction of the Alkaline Earth Metal Alloy with Gaseous Media
}

\author{
S.E. Sarkisov, V.V. Ryabchenkov, V.A. Yusim, R.K. Kalimullin, \\ V.P. Mikhailov, Ju.V. Shirokovskaya \\ National Research Center «Kurchatov Institute», Moscow, 123182, Russia \\ nrcki@nrcki.ru
}

\begin{abstract}
The sorption method of inert gases deep purification from unwanted chemically active impurities is offered on an example of chemical reactions between components that make up air and $\mathrm{Ca}-\mathrm{Mg}$ alkaline-earth alloy process investigation.

Keywords: alkaline earth metal alloys, chemical compounds, adsorption, gas cleaning
\end{abstract}




\title{
Физико-химические процессы взаимодействия сплава щелочноземельных металлов с газовыми средами
}

\author{
С.Э. Саркисов, В.В. Рябченков, В.А. Юсим, Р.К. Калимуллин, \\ В.П. Михайлов, Ю.В. Широковская \\ НИЦ Курчатовский институт, Россия, Москва, 123182, пл. Академика Курчатова, д. 1 \\ nrcki@nrcki.ru
}

\begin{abstract}
Аннотация
Предложен способ высокой очистки инертных газов от нежелательных химически активных газообразных примесей на примере изучения процесса химического взаимодействия щелочноземельного Са-Mg сплава с компонентами воздушной среды.
\end{abstract}

Ключевые слова: сплавы щелочноземельных металлов, химические соединения, адсорбция, газоочистка

\section{1. Введение}

Настоящая работа связана с проводимыми нами исследованиями в области получения сверхчистых инертных газов, в частности, гелия, аргона и ксенона. Газообразные примеси такие, как кислород, азот, водород, являются элементами, широко распространенными в окружающей среде следствием чего их трудно удалить из очищаемого вещества и, наоборот, легко загрязнить уже чистый материал. Поэтому эти примеси чаще всего ограничивают чистоту вещества в целом. Предел обнаружения для газообразующих и распространенных элементов находится на уровне $10^{-6}$ масс.\% [1]. Сверхчистые инертные газы играют существенную роль в технологии получения высокочистых перспективных материалов для микроэлектроники, квантовой электроники, медицины и многого другого, где специфические свойства высокочистых веществ приносят новые возможности в области практического применения. В основе глубокой очистки лежат методы разделения, которые используют какой-либо разделительный эффект, обусловленный различием свойств примеси и очищаемого вещества. Все используемые в настоящее время методы глубокой очистки веществ по природе эффекта, лежащего в их основе, разделяются на три группы: химические, физико-химические и физические методы [1].

В настоящей работе, впервые, в качестве альтернативы общепринятым геттерным и криогенным технологиям [2], задача очистки многокомпонентной газовой среды от ее отдельных составляющих, решена сочетанием химических и физико-химических (адсорбционно-диффузионных) методов сепарации с физическими методами их определения. Адсорбентом являлся мелко измельченный порошок реакционного сплава из щелочноземельных металлов, которые сорбируют газы путем роста химических соединений на поверхности частицы металла. Задача состояла в исследовании химической активности материала реакционного сплава по взаимодействию с компонентами воздуха (адсорбат), в первую очередь в отношении кислорода, азота, влаги и образующихся побочных продуктов протекающих химических реакций с участием основных компонентов. Важную роль в процессах адсорбционной газоочистки играет способ контактирования газовой смеси с адсорбентом или иначе - режим работы адсорбента. Обычно, в качестве адсорбентов используются пористые (геттерные) ма- 
териалы с развитой внутренней поверхностью, характеризующейся параметром - удельная поверхность $\left(S_{\text {уд }}, \mathrm{M}^{2} / \Gamma\right)$. В данной работе использовался фильтрующий режим газоочистки, а развитая внутренняя удельная поверхность адсорбента, повышающая сорбционную емкость реакционных металлов, создавалась слоем частиц микронного размера химически активного сорбционного сплава.

\section{2. Получение реакционного сплава}

Изготовление химически активного сплава состава Сa-10\% $\mathrm{Mg}$ осуществляли в высокотемпературной трубчатой вакуумной печи при температурном режиме, в соответствии с фазовой диаграммой $\mathrm{Ca}-\mathrm{Mg}$, исследованию которой посвящено большое число экспериментальных работ, подробный обзор которых можно найти в справочной литературе [3]. Слитки сплава получали в тонкостенных тиглях из нержавеющей стали (рис. 1).

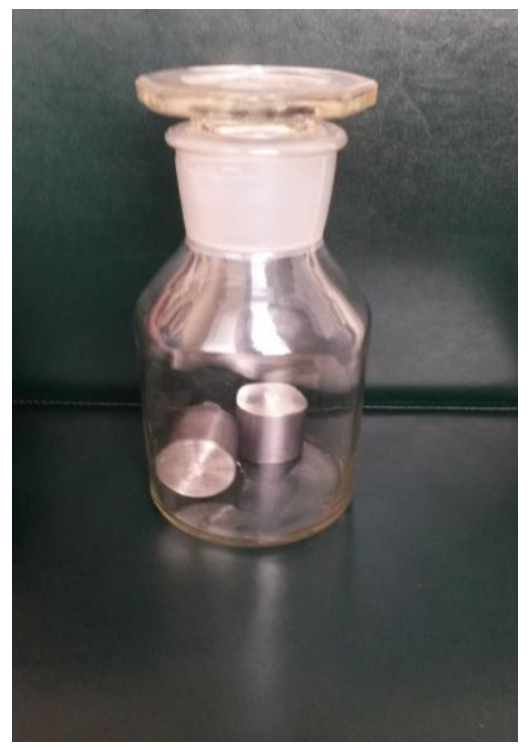

Рис. 1. Слитки Са-10\% Mg сплава в тиглях в атмосфере аргона

Тигель с шихтой помещали в печь, откачивали объем до $10^{-3}$ мм.рт.ст., после $200^{0} \mathrm{C}$ напускали аргон высокой чистоты (не менее $99.998 \%$ ) до давления выше 500 мм.рт.ст., доводили шихту до плавления, выдерживали $10 \div 15$ минут и затем охлаждали до комнатной температуры при включенной откачки. В вакуумном перчаточном боксе, заполненном аргоном, сплав дробили фрезой до мелкодисперсного состояния и полученный порошок с размером частиц $2 \div 5$ микрон засыпали в газопроницаемый контейнер (картридж) цилиндрической формы с диаметром 70 мм и толщиной 40 мм. Контейнер с металлическим Са-Mg порошком помещался в лабораторную экспериментальную установку (рис. 2), в которой производился сорбционно-химический процесс взаимодействия с компонентами атмосферной воздушной среды.

Установка соединялась с квадрупольным масс-спектрометром Pfeiffer HiCube 80Eco, данные с которого записывались количественно в цифровом виде и графически отображались на мониторе ноутбука Самсунг в виде спектров динамического развития в реальном времени, протекающих в сорбционной установке химических процессов.

\section{3. Адсорбция газов на поверхности металлов}

Адсорбцией называют изменение концентрации вещества на границе раздела фаз. Адсорбционное равновесие, т.е. равновесное распределение вещества между пограничным слоем и граничащими фазами, является динамическим и быстро устанавливается. Частицы, которые находятся на поверхности твердого тела, обладают избыточной энергией и за счет это- 
го молекулы окружающей среды притягиваются к металлу и концентрируются на его поверхности. Этот процесс протекает всегда самопроизвольно и с положительным тепловым эффектом $[4,5]$.

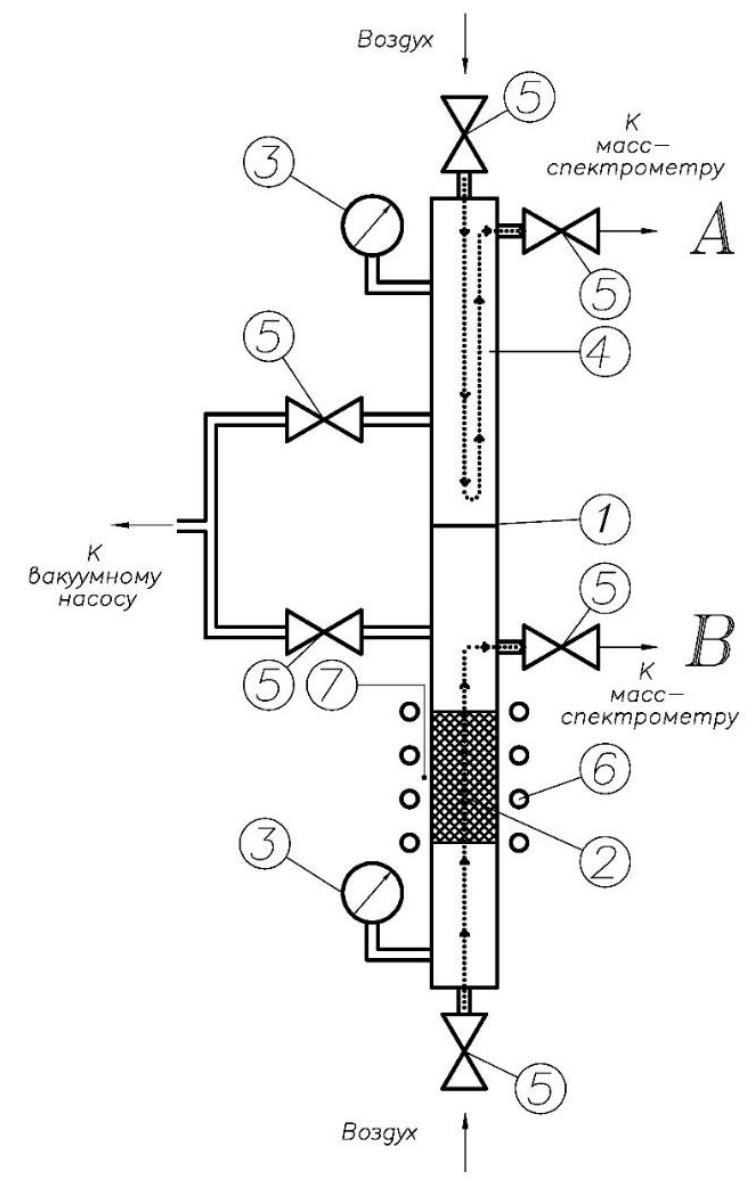

Рис. 2. Блок-схема сорбционной установки: 1 - перегородка, 2 - контейнер с адсорбентом из щелочноземельных металлов, 3 - монометры, 4 - корпус установки, 5 - вакуумные вентили, 6 - электрическая печь, 7 - термопара

Количество адсорбированного вещества, отнесенное к единице поверхности, зависит от температуры среды и концентрации адсорбата в газовой или жидкой фазе. Количественной характеристикой адсорбционной системы является изотерма адсорбции. Она показывает зависимость между количеством поглощенного вещества $a$ и его давлением $p$ (или концентрацией $у$ для жидкости) в объеме фазы при постоянной температуре в условиях адсорбционного процесса

$$
a=f(p)_{T}=f(y)_{T}
$$

Наиболее простой случай количественного описания адсорбционных процессов - адсорбция газов. Экспериментально полученные изотермы и изобары адсорбции - основной источник информации для понимания и расчета адсорбционных процессов. Скорость адсорбции $v_{\text {ад }}$ прямо пропорциональна давлению газа $P$ и величине свободной поверхности металла

$$
v_{\text {ад }}=K_{\text {ад }} P(1-\theta),
$$

где $\theta$ - доля поверхности, покрытая адсорбируемыми молекулами; $K_{\text {ад }}-$ константа, характеризующая скорость процесса адсорбции. 
Скорость обратного процесса - десорбции будет прямо пропорциональна поверхности, занятой реагирующими молекулами

$$
v_{\text {дес }}=K_{\text {дес }} \theta
$$

При установлении равновесия в адсорбционном процессе скорость адсорбции равна скорости десорбции

или

$$
\begin{gathered}
v_{\text {ад }}=v_{\text {дес }} \\
K_{\text {ад }} P(1-\theta)=K_{\text {дес }} \theta
\end{gathered}
$$

Здесь величина $(1-\theta)$ означает долю свободных активных центров адсорбции.

Из уравнения (5) относительно $\theta$ получим

$$
\theta=\frac{K_{\text {ад }} P}{K_{\text {дес }}+K_{\text {ад }} P}
$$

или можно записать, как

$$
\theta=\frac{a P}{1+a P}
$$

где $a$ - адсорбционный коэффициент.

Уравнение (7) носит название изотермы Ленгмюра. Её графическое выражение дано на рис. 3.

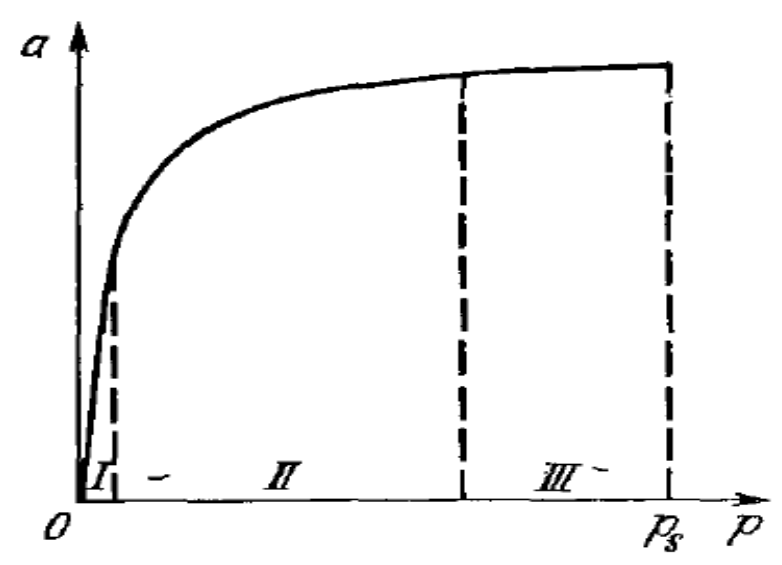

Рис. 3. Общий вид изотермы Ленгмюра

При $\theta=1$ получается горизонтальный участок (III), отвечающий образованию заполненного монослоя. Это означает, что все активные центры на поверхности металла полностью заполнены адсорбированным веществом и дальнейшее увеличение его парциального давления в газовой фазе не влияет на количество вещества, адсорбированного на поверхности твердого тела.

При низком давлении газа

$$
\theta=a P
$$

То есть, если $1+a P \sim 1$, то при этих условиях степень заполнения поверхности мала и пропорциональна давлению. Выражение (8) отражает закон распределения и носит название изотермы Генри. В соответствии с законом Генри число молекул, соударяющихся с поверхностью в единицу времени, пропорционально давлению газа, а вероятность молекулы найти незанятую площадку пропорциональна числу молекул. 
Для удаления микропримеси должен быть использован адсорбент, обладающей высокой селективностью именно к микропримеси. Поскольку в исходных чистых веществах, которые поступают на глубокую очистку, соотношение концентраций основного вещества и микропримеси отвечает величине $\sim 10^{5}$ то, даже если селективность адсорбента по микропримеси равна $10^{3}$, отношение степеней заполнения поверхности микро- и макрокомпонентами находится в диапазоне $0.1 \div 0.001$ [6]. Другими словами, очень незначительная доля активной поверхности адсорбента используется при адсорбции микропримесей $[7,8]$.

В большинстве случаев поверхность твердого металла адсорбента энергетически неоднородна. Она представляет собой серию элементарных площадок, обладающих различной теплотой адсорбции. Экспериментальные данные более точно описываются уравнением

$$
\theta=f^{-1} \ln a_{0} P,
$$

где $f$ - коэффициент, отражающий функцию распределения; $a_{0}$ - адсорбционный коэффициент при наибольшей теплоте адсорбции. Выражение (9) получило название логарифмической изотермы адсорбции. Экспериментально она впервые была описана в работах А.Н. Фрумкина и А.И. Шлыгина [9]. Адсорбция может быть мономолекулярной и полимолекулярной. В последнем случае на поверхности адсорбента образуется несколько слоев. Первый мономолекулярный слой обусловлен силами взаимодействия между поверхностью твердого тела и адсорбатом. Второй и последующие слои удерживаются ван-дер-ваальсовскими силами. Слои адсорбата распределяются по поверхности неравномерно. На некоторых участках их может быть два или три слоя. На рис. 4 представлена изотерма адсорбции кислорода [10]. Участки $a b$ и $b c$ отвечают мономолекулярной адсорбции, участок $c d-$ полимолекулярной.

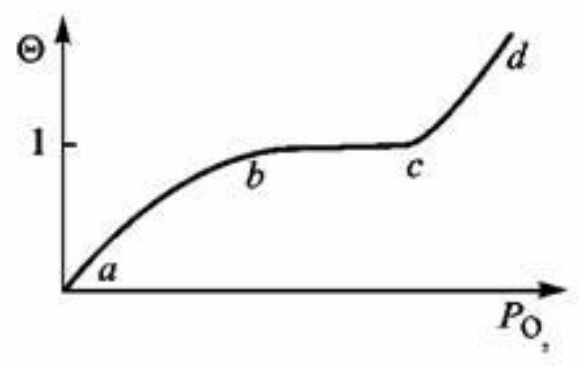

Рис. 4. Изотерма адсорбции кислорода

На рис. 5 показаны два типа сорбционного поведения металлов (кривые 1 и 2), которые используются в геттерных технологиях $[11,12]$.

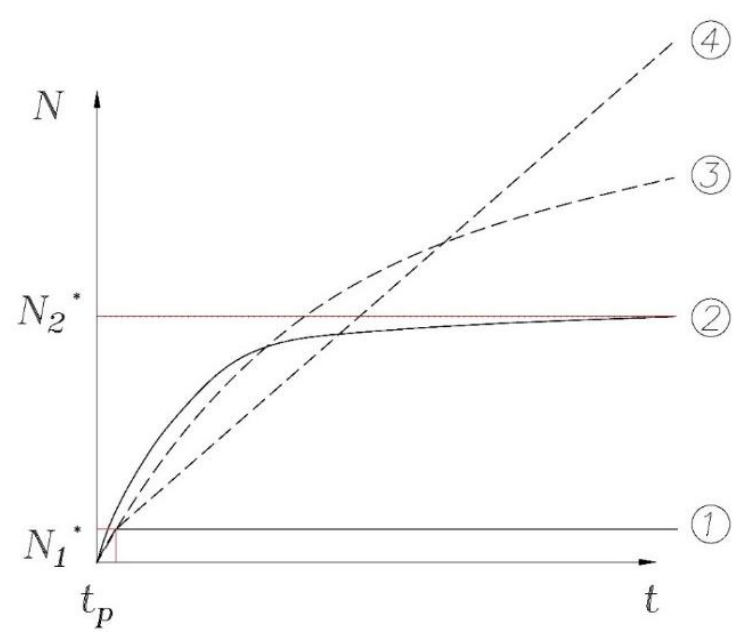

Рис. 5. Сорбционное поведение металлов согласно кинетическому закону $N(t)$ 
Здесь $N$ - количество газа, сорбированного единицей площади поверхности металла к моменту времени $t$. Кривая 1 описывает сорбционный закон для переходных металлов вроде $\mathrm{Ti}, \mathrm{V}, \mathrm{Zr}, \mathrm{Ni}$ и др. при комнатной температуре. Адсорбция прекращается при $t=t_{p}$, когда поверхность насыщается атомами газа. Этому пассивированному состоянию отвечает предельное значение $N_{1}^{*}$. Кривая 2 описывает случай абсорбции, когда газы растворяются в объеме геттерного материала. Величина $N$ при абсорбции асимптотически приближается к значению $N_{2}^{*}$, которое ограничено максимальной растворимостью газа в металлах данного класса.

Поведение процессов сорбции (пунктирные линии), описываемых зависимостями, которые следуют параболическому закону $N_{3}$ (кривая 3 ) или линейному $N_{4}$ (кривая 4) должны быть характерны для случаев, когда в соответствии с кинетическим законом $N(t)$, идет непрерывный процесс и до конца, т.е. когда идут химические реакции газовых компонент с реакционными металлами до тех пор, пока весь металл не будет израсходован в результате реакции $\mathrm{Me}+\mathrm{X}=\mathrm{MeX}$, где $\mathrm{Me}$ - металл, $\mathrm{X}$ - сорбируемый газ, $\mathrm{MeX}$ - продукт реакции. К таким реакционным сорбентам относятся щелочные и щелочноземельные металлы и их сплавы. В итоге можно записать соотношение предельных значений $N^{*}$

$$
N_{4}^{*}=N_{3}^{*}>N_{2}^{*} \gg N_{1}^{*}
$$

\section{4. Результаты и их обсуждение}

Изучалось химическое взаимодействие частиц щелочноземельного сплава с газовыми компонентами воздуха (основной состав по массе: $\mathrm{N}_{2}-75.5 \% ; \mathrm{O}_{2}-23.15 \% ; \mathrm{H}_{2} \mathrm{O}$ - влага). Исследования проводились в двухкамерном химическом реакторе (сорбционной установке), показанном на рис. 2. Камеры, разделенные перегородкой (1), предварительно откачивались до давления $10^{-4}$ мм.рт.ст. и затем в них подавались исследуемые образцы воздушной среды в равных объемах до установления по манометрам (3) постоянного давления 600 мм.рт.ст. Из каждой камеры пробы воздуха по каналам А и В, подавались в рабочую камеру массспектрометра (РК М-С) для измерений. Сначала в масс-спектрометр из верхней камеры по каналу А напускался объем пробы исходного, не прошедшего взаимодействия с щелочноземельным сорбентом воздуха, а затем из нижней камеры по каналу В, напускалась проба воздуха, прошедшего через сорбент (2).

На рис. 6-8 представлены спектрограммы динамики развития во времени, проходящего процесса химического взаимодействия частиц активного щелочноземельного сплава с газообразными компонентами (сорбции газообразных примесей) в исследуемых пробах воздуха в рабочем объеме вакуумной камеры масс-спектрометра.

Обзорная спектрограмма детектируемых газообразных компонентов и динамики их развития во времени при давлении в рабочей камере масс-спектрометра в диапазоне $10^{-7} \div 10^{-8}$ мм.рт.ст. при комнатной температуре показана на рис. 6 . Интенсивности пиков соответствуют чувствительности масс-спектрометра к основным и побочным компонентам. Для усиления слабоинтенсивных пиков газообразных компонентов на рис. 7 и 8 при комнатной температуре и $T=330^{\circ} \mathrm{C}$ показаны спектрограммы, снятые в режиме повышенной чувствительности масс-спектрометра при увеличении вакуума РК М-С до $10^{-9}$ и $10^{-10}$ мм.рт.ст., соответственно. На рис. 7. показано поведение сорбции молекулярного азота при комнатной и повышенной до $330^{\circ} \mathrm{C}$ температуре. Нагрев был включен на 12-й минуте опыта.

В Таблице 1 приведены результаты по сорбционной динамике основных и побочных газовых компонент, рассчитанные по спектрограммам рис. 6-8. Основными газовыми компонентами исследованных образцов воздушных проб являются $\mathrm{N}_{2}$ (молекулярный азот), $\mathrm{N}$ (атомарный азот), $\mathrm{O}_{2}$ (молекулярный кислород) и $\mathrm{H}_{2} \mathrm{O}$ (влага). Побочными газовыми компонентами - продуктами химических реакций металлов сплава и их соединений с основными газовыми компонентами, являются $\mathrm{H}_{2}$ (водород) и $\mathrm{NH}_{3}$ (аммиак). 


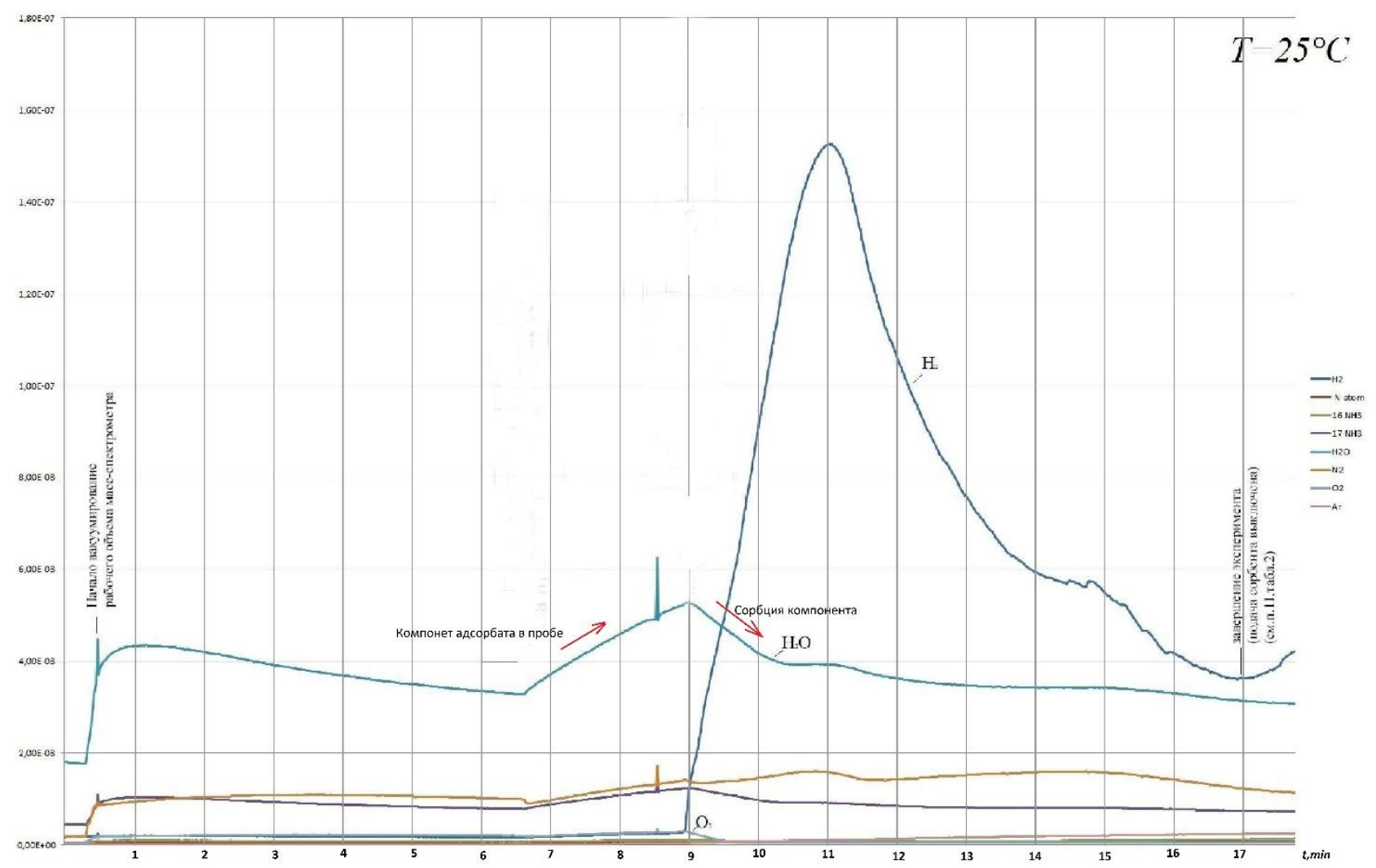

Рис. 6. Обзорный спектр сорбции основных и побочных компонентов адсорбата

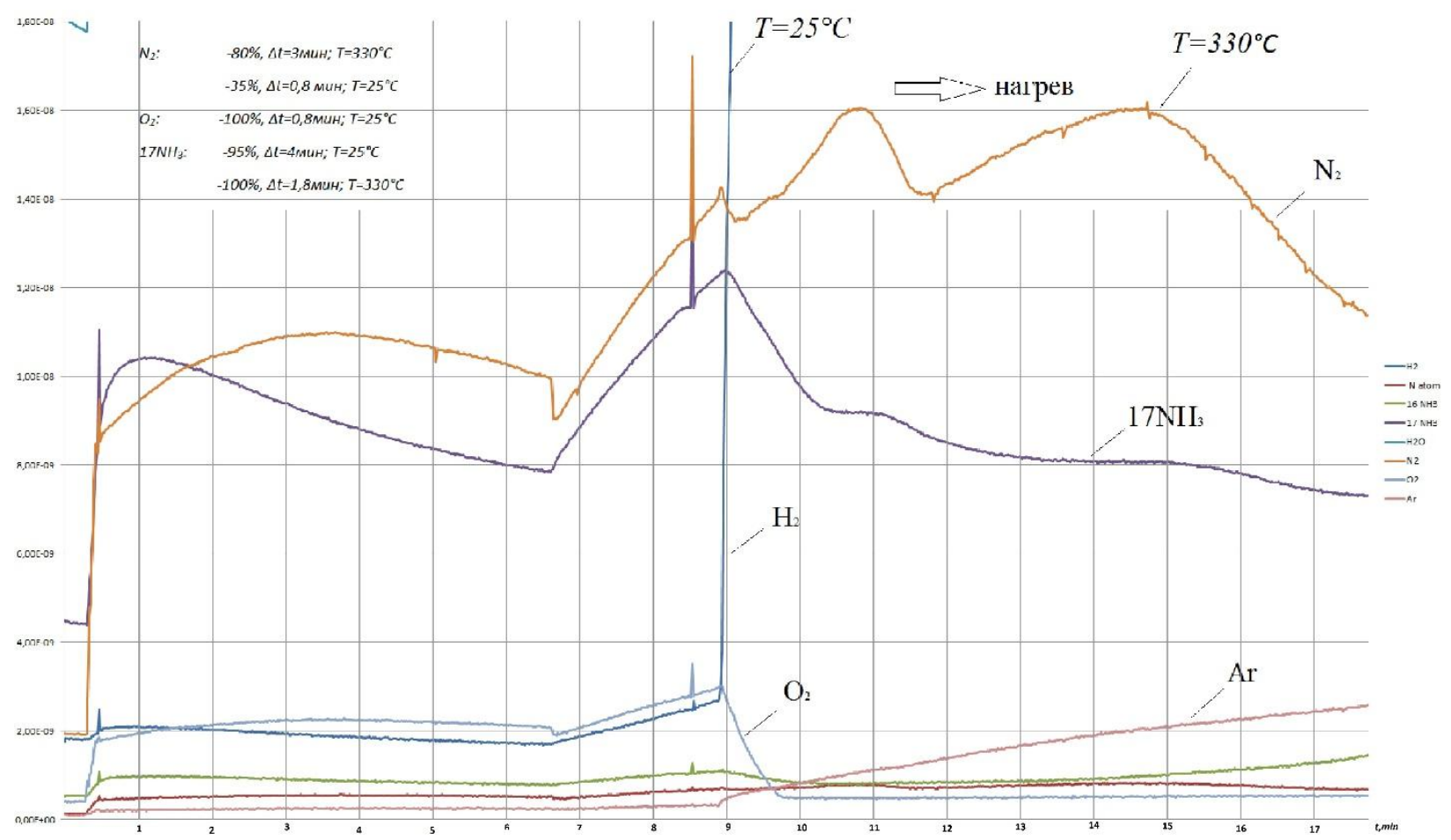

Рис. 7. Спектры сорбции $\mathrm{O}_{2}, \mathrm{~N}_{2}$ и $17 \mathrm{NH}_{3}$ в пробах адсорбата 


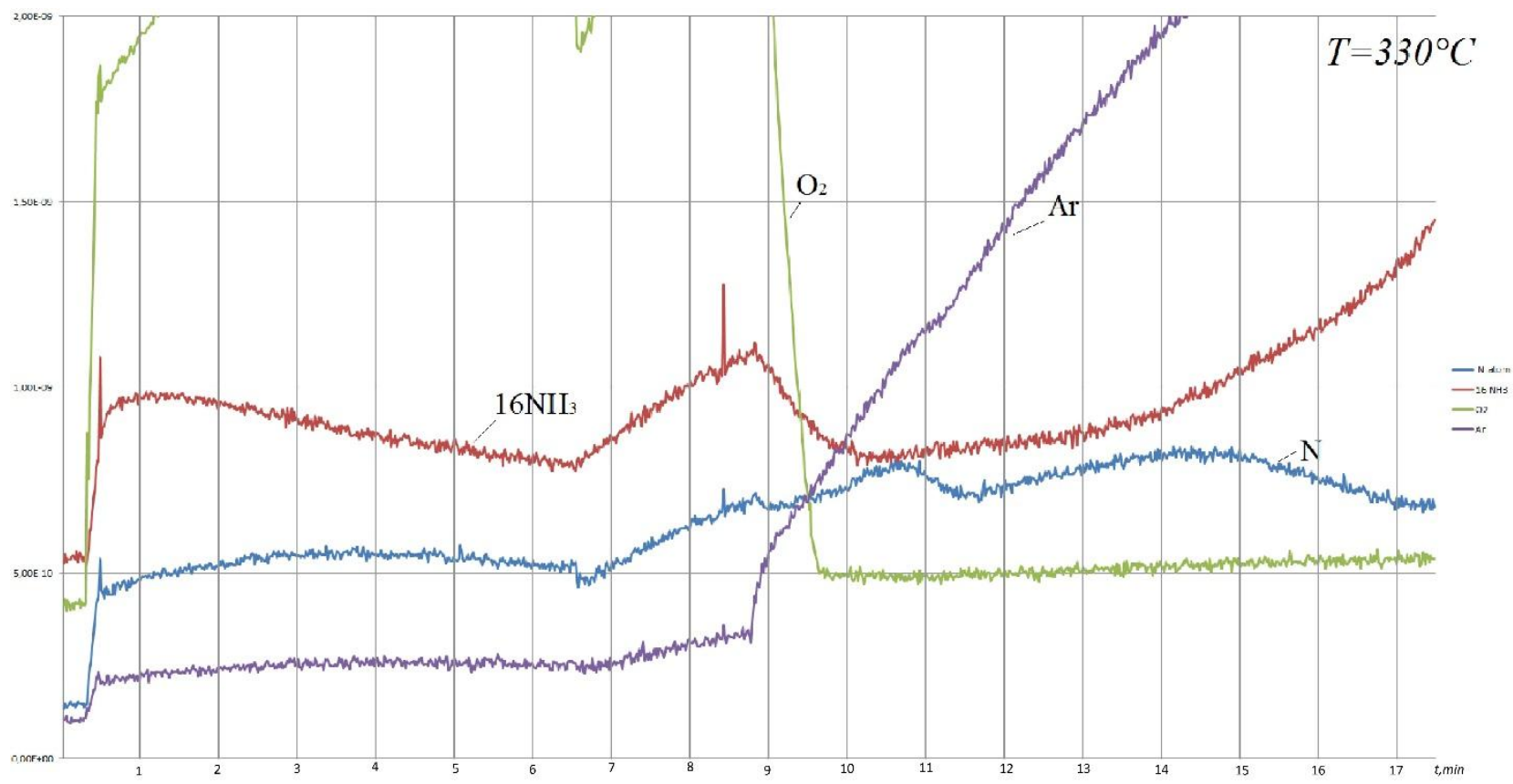

Рис.8. Детальные температурные спектры сорбции аммиака-16 и атомарного азота

Таблица 1

\section{Сорбционная активность Са-10\% Мg сплава}

\begin{tabular}{|l|c|c|c|c|c|}
\hline $\begin{array}{c}\text { Газообразный } \\
\text { компонент }\end{array}$ & $\begin{array}{c}\text { Время достиже- } \\
\text { ния максимума } \\
\text { компонентом } \\
\text { адсорбата в РК } \\
\text { М-С, } \Delta t \text { мин }\end{array}$ & $\begin{array}{c}\text { Величина } \\
\text { сорбции ком- } \\
\text { понента ад- } \\
\text { сорбата, \% }\end{array}$ & $\begin{array}{c}\text { Время сорбции } \\
\text { компонента ад- } \\
\text { сорбата, } \Delta t \text { мин }\end{array}$ & $\begin{array}{c}\text { Температура } \\
\text { проведения } \\
\text { опыта } T^{\text {0 }} \mathrm{C}\end{array}$ & Примечание \\
\hline Кислород $\left(\mathrm{O}_{2}\right)$ & 2.2 & 100 & 0.8 & 25 & Рис.6, 7 \\
\hline Азот $\left(\mathrm{N}_{2}\right)$ & 2.0 & $35 ; 80$ & $0.8 ; 3.0$ & $25 ; 330$ & Рис.7 \\
\hline Азот $(\mathrm{N})$ & 3.8 & $40 ; 100$ & $1.0 ; 2.3$ & $25 ; 330$ & Рис. 8 \\
\hline Влага $\left(\mathrm{H}_{2} \mathrm{O}\right)$ & 2.5 & $40 ; 100$ & $1.4 ; 6.0$ & 25 & Рис.6 \\
\hline Водород $\left(\mathrm{H}_{2}\right)$ & 2.2 & $40 ; 85$ & $2.8 ; 6.5$ & 25 & Рис.6 \\
\hline Аммиак $(16)$ & 2.4 & 100 & 1.3 & 330 & Рис. 8 \\
\hline Аммиак $(17)$ & 2.4 & $95 ; 100$ & $4.0 ; 1.8$ & $25 ; 330$ & Рис.7 \\
\hline
\end{tabular}

Примечание: Наличие аргона (Ar) зафиксированного на спектрограммах связано с его использованием при изготовлении Са-Mg сплава, в результате чего объем сплава насыщается аргоном. С повышением температуры частиц в колонке сорбционного аппарата абсорбированный аргон начинает выделяться (см. рис. 7,8 .). Наличие группы $16 \mathrm{NH}_{3}$ может быть связано с аминогруппой $\mathrm{NH}_{2}$ (молекулярная масса 16) при замене одного атома водорода на ОН-группу с образованием гидроксиламина $\mathrm{NH}_{2} \mathrm{OH}$, который при повышенной температуре разлагается с образованием аммиака, азота и воды: $\mathrm{NH}_{2} \mathrm{OH} \rightarrow \mathrm{NH}_{3}+\mathrm{N}_{2}+\mathrm{H}_{2} \mathrm{O}$. В колонках таблицы, следует сопоставлять друг с другом параметры, выделенные конкретным цветом (например, величина сорбции компонента адсорбата Азот $\left(\mathrm{N}_{2}\right) 80 \%$ - красный цвет, время сорбции 3.0 минуты, температура сорбции $\left.330^{\circ} \mathrm{C}\right)$.

Результаты, приведенные в табл. 1 показывают, что при создании определенных температурных условий величина сорбции основных и побочных газообразных компонентов может достигать $80 \div 100 \%$. Для выбора наиболее эффективных сорбентов необходимо синте- 
зировать новые виды сплавов, сочетающие элементы щелочных и щелочноземельных металлов. Основу реакционных газосорбентов рассматриваемой технологии химической очистки инертных газов могут составлять двойные, тройные и более многокомпонентные сплавы на основе $\mathrm{Ca}, \mathrm{Mg}, \mathrm{Ba}$ с добавками $\mathrm{Al}, \mathrm{Li}$ и $\mathrm{Sr}$. Концентрация основных реакционных металлов в этих сплавах должна быть не менее 50 \%. Именно при указанном условии и тонком измельчении реакционного сплава химическая сорбция газов должна протекать по механизму поверхностных реакций и будет идти до конца. Химические реакции, протекающие при сорбции газообразных компонент и обусловливающие общую кинетику протекающих процессов, приведены в Таблице 2 .

Таблища 2

Химические реакции процесса газоочистки

\begin{tabular}{|c|c|c|c|}
\hline № & Реакции кальция & № & Реакции магния \\
\hline 1 & $\mathrm{Ca}+\underset{\uparrow}{2 \mathrm{H}_{2} \mathrm{O} \rightarrow \underset{\left(\text { oбp. } \mathrm{H}_{2}\right)}{\mathrm{Ca}(\mathrm{OH})_{2}+\mathrm{H}_{2}}}$ & 7 & $\mathrm{Mg}+2 \mathrm{H}_{2} \mathrm{O} \rightarrow \mathrm{Mg}(\mathrm{OH})_{2}+\mathrm{H}_{2} \uparrow\left(\right.$ обр. $\left.\mathbf{H}_{2}\right)$ \\
\hline 2 & $\mathrm{Ca}+\mathrm{H}_{2} \rightarrow \mathrm{CaH}_{2}$ (сорбция $\boldsymbol{H}_{2}$ ) & 8 & $\mathrm{Mg}+\mathrm{H}_{2} \rightarrow \mathrm{MgH}_{2}$ (сорбция $\mathbf{H}_{2}$ ) \\
\hline 3 & $3 \mathrm{Ca}+\mathrm{N}_{2} \rightarrow \mathrm{Ca}_{3} \mathrm{~N}_{2}$ (сорбция $\mathrm{N}_{2}$ ) & 9 & $3 \mathrm{Mg}+\mathrm{N}_{2} \rightarrow \mathrm{Mg}_{3} \mathrm{~N}_{2}$ (сорбция $\mathbf{N}_{2}$ ) \\
\hline 4 & $\begin{aligned} \mathrm{Ca}_{3} \mathrm{~N}_{2}+6 \mathrm{H}_{2} \mathrm{O} & \rightarrow 3 \mathrm{Ca}(\mathrm{OH})_{2} \\
& +2 \mathrm{NH}_{3}\left(\text { oбp. } \mathbf{N H}_{3}\right)\end{aligned}$ & 10 & $\begin{aligned} \mathrm{Mg}_{3} \mathrm{~N}_{2}+8 \mathrm{H}_{2} & \rightarrow 3 \mathrm{Mg}(\mathrm{OH})_{2} \\
& +2 \mathrm{NH}_{3} \cdot \mathrm{H}_{2} \mathrm{O}\left(\text { обр. } \mathbf{N H}_{3}\right)\end{aligned}$ \\
\hline 5 & $\begin{array}{l}6 \mathrm{Ca}+2 \mathrm{NH}_{3} \\
\rightarrow \mathrm{Ca}_{3} \mathrm{~N}_{2}+3 \mathrm{CaH}_{2} \text { (сорбция } \mathbf{N H}_{3} \text { ) }\end{array}$ & 11 & $\begin{aligned} 3 \mathrm{Mg}+2 \mathrm{NH}_{3} \rightarrow & \mathrm{Mg}_{3} \mathrm{~N}_{2}+3 \mathrm{H}_{2} \\
& \uparrow\left(\text { сорбция } \mathbf{N H}_{3} \text { с обр. } \mathbf{H}_{2}\right)\end{aligned}$ \\
\hline 6 & $2 \mathrm{Ca}+\mathrm{O}_{2} \rightarrow 2 \mathrm{CaO}\left(\right.$ сорбция $\left.\mathbf{O}_{2}\right)$ & 12 & $2 \mathrm{Mg}+\mathrm{O}_{2} \rightarrow 2 \mathrm{MgO}\left(\right.$ сорбция $\mathbf{0}_{2}$, легко $)$ \\
\hline
\end{tabular}

Примечание: Жирным шрифтом выделены, образующиеся побочные продукты химических реакций с основными газовыми компонентами и их химические реакции (сорбция) с щелочноземельными металлами. Исключив $\mathrm{H}_{2} \mathrm{O}$ путем предварительного вымораживания в азотной ловушке перед напуском воздуха (газа) в химический реактор можно избавиться от нежелательных побочных продуктов реакций $-\mathrm{H}_{2}$ и $\mathrm{NH}_{3}$ (реакции: $1,4,7,10,11$ ).

\section{5. Заключение}

Результаты показывают, что процесс проведения химических реакций в фильтрующем режиме (или режиме кипящего слоя) с использованием щелочноземельных металлов в качестве сорбционных материалов, является эффективным методом высокой очистки любых газов, в том числе инертных от нежелательных газообразных примесей. Этот метод является альтернативным по отношению к традиционным методам очистки газов, таким как геттерная очистка (где необходимо наличие химического сродства между сорбентом и сорбатом), а также криогенному способу. К преимуществам настоящего метода относится:

- отсутствие источников загрязнения, которые появляются в геттерных технологиях, использующих высокотемпературный (до $2000^{\circ} \mathrm{C}$ ) нагрев очищающего материала. Как известно, повышение температуры стимулирует реакции с образованием летучего побочного продукта, а также увеличивает диффузную подвижность газовых частиц через стенку колонны;

- $\quad$ сверхвысокая реакционность измельченных твердых тел при комнатной температуре. Порошки, получаемые механическим разрушением активных сплавов обеспечивают ускоренное протекание реакций и диффузионных процессов;

- $\quad$ высокая сорбционная емкость реакционных щелочных и щелочноземельных металлов на порядки величины больше, чем у переходных металлов, используемых в геттерных технологиях. Это случай, когда реакционные металлы в отличие от геттерных материа- 
лов сорбируют газы непрерывно и до конца, пока весь металл не будет израсходован в результате химической реакции с адсорбатом;

- $\quad$ использование для газоочистки реакционных порошков, стоимость которых в десятки раз ниже, чем у геттерных металлов $\mathrm{Zr}, \mathrm{V}$, Ti и др. - намного выгоднее экономически.

Известно, что геттерные и криогенные газоочистительные системы коммерчески выгодны при условии, что входящий в систему газ имеет чистоту не ниже $4.5 \mathrm{~N}$, т.e. содержит $99.995 \%$ основного вещества [13]. Полученные результаты эффективной сорбции компонент, составляющих воздух (т.е., когда их относительная концентрация очень высокая), позволяют предположить, что он тем более должен быть рентабельным в случае, когда исходным продуктом будет служить, например, инертный газ даже технической чистоты $90 \div 99 \%$, т.е. когда концентрация примесей азота, кислорода, влаги и др. на порядки ниже, чем в составе воздуха. Представленный новый метод газоочистки в этом отношении является прорывным событием в области геттерной очистки.

\section{Благодарности и ссылки на гранты}

Авторы выражают благодарность директору ИФХЭ РАН профессору А.К.Буряку и сотрудникам института за поддержку и помощь в спектральных измерениях. Работа выполнена при финансовой поддержки грантов РФФИ № 18-08-00291, № 17-08-00963.

\section{Литература}

1. Серпионова Е.Н. Промышленная адсорбция газов и паров. М.: «Высш. школа», 1969, 416 с.

2. Головко Г.А. Криогенное производство инертных газов. Л.: Машиностроение, Ленинградское отделение, $1983.416 \mathrm{c}$.

3. Диаграммы состояния двойных металлических систем ред. Лякишева Н.П. Машиностроение, 1996-2000 гг.

4. Девятых Г.Г., Елиев Ю.Е. Введение в теорию глубокой очистки веществ. М.: Наука, 1981. 320 c.

5. Степин Б.Д., Горштейн И.Г., Блюм Г.З., Курдюмов Г.М., Оглоблина И.П. Методы получения особо чистых веществ. М.: Химия, 1969. 480 с.

6. Кельцев Н.В. Основы адсорбционной техники. М.: Химия, 1984. 592 с.

7. Молоканов Ю.К., Кораблина Т.П., Клейновская М.А., Щелкунова М.А. Разделение смесей кремний органических соединений. М.: Химия, 1974. 296 с.

8. Зельвенский Я.Д., Титов А.А., Шалыгин В.А. Ректификация разбавленных растворов. Л.: Химия, Ленинградское отделение. 1974. 216 с.

9. Фрумкин А.Н., Шлыгин А.И. О платиновом электроде. Докл. АН СССР, 1934, т.2, №3, с.173.

10. Шумяцкий Ю.И., Афанасьев Ю.М. Адсорбция: процесс с неограниченными возможностями. М.: «Высш. школа», 1998, 78 с.

11. Hseuh H.C., Lanni C. J.Vac.Sci.Technol. A. 1983, v.1(2), pp. 1283-1287.

12. Giorgi T.A. Appl. Phys. Suppl. 1974, v.2, pp.1-53.

13. SAES Getters Inc. Megatorr brochure. 2003. 